\title{
Could Chemical Composition of Stone Influence Percutaneous Nephrolithotomy in the Management of Staghorn Calculi?
}

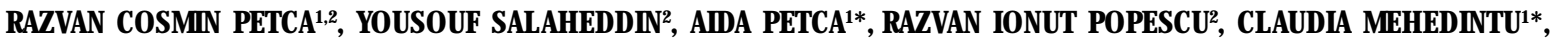 \\ NICOLETA MARU ${ }^{1}$, VIOREL JINGA ${ }^{1,2}$ \\ ${ }^{1}$ Carol Davila University of Medicine and Pharmacy, 8 Eroii Sanitari Blvd., 050474, Bucharest, Romania \\ 2Prof. Dr. Th. Burghele Clinical Hospital, 20 Panduri Str., 050653, Bucharest, Romania
}

\begin{abstract}
The management of large renal stones is a challenging situation for the urologists. PCNL (percutaneous nephrolithotomy) represents the elective procedure and can be performed as monotherapy or combined with other techniques. This is a retrospective study on 75 patients diagnosed with staghorn calculi at Prof. Dr. Th. Burghele Clinical Hospital who underwent PCNL between 01.01.2018 to 31.06.2018. The aim of this study is to evaluate the correlations between the staghorn chemical composition, the stone free rate and the complication rate after surgery according to modified Clavien Dindo system of evaluation for urological procedures.
\end{abstract}

Keywords: PCNL, staghorn calculi, Clavien-Dindo, residual stone, complications

The term of staghorn calculus is typically used for stones located in the renal pelvis with branches in one or more calyces and is usually associated with chronic infections. Recurrent infections with urease producing germs leads to crystallization and formation of branched stones in the pyelocaliceal system [1,2]. Irrespective of the chemical composition, the present guidelines suggest surgical approach for a newly diagnosed patient because of the potential high risk to destroy the kidney and more dangerous, the imminence of urosepsis.

Several methods are used as treatment for staghorn calculi, in monotherapy or combined therapy. The firstline of treatment recommended by actual guidelines is PCNL (percutaneous nephrolithotomy). It can be chose as monotherapy or combined with ESWL (extracorporeal shock wave lithotripsy) [3,4]. PCNL is generally considered a safe procedure with a low postoperative complication rate. The most common complications are: perforations of the surrounding organs (colon, liver, spline, lung, pleura), bleeding, fever, lumbar collections (urinoma, hematoma) [5-7] that can appear as early as the initial puncture time until after a few weeks' time. For grading the complications most surgeons use the Clavien-Dindo system. Recent studies revealed that urologists have a lower rate of agreement in classifying minor complications compared to major complications based on this classification $[6,8]$.

According to the 2005 AUA Guideline, staghorn stones are mostly composed of struvite and calcium carbonate apatite, occasionally with cystine or uric acid are found and rarely calcium oxalate and phosphate [3]. Even though the term of staghorn calculi is classically synonymous with infection stones, recent studies revealed changing aspects in the chemical structure of this pathology leading to an increased number of cases with a metabolic origin. This may have a notable impact on the success rate and complications management after PCNL.

The pathophysiology of stone formation is extremely diverse and includes complex mechanisms that leads to crystallization. The stones chemical composition depends on the pathogenic condition that leads to their formation. Calcium nephrolithiasis includes calcium oxalate and calcium phosphate ones. Calcium oxalate is considered by most studies to be most frequent. Randall et al [9] is one of the first scientists who described a type of lesions in the renal papillae (Randall plaques), which are present in cases of calcium oxalate lithiasis. Some of the causes involved in calcium stones formation are: absorptive hypercalciuria, hyperparathyroidism, immobilization, excess of sodium and proteins in diet, renal tubular acidosis, bowel pathology, high purine intake, drug-induced uricosuria and genetic primary renal leak [10-12].

Uric acid stones are considered to be the result of hyperuricosuria, modified urinary $\mathrm{pH}$ or both. This conditions lead to precipitation of uric acid. The clinical picture associated with this type of lithiasis is usually with high BMI, glucose intolerance and type 2 diabetes [13-15].

Infection stones are considered to be due to alterations in the urinary chemistry caused by microbial proliferations. The most frequent type is magnesium ammonium phosphate $\left(\mathrm{NH}_{4} \mathrm{MgPO}_{4} \cdot 6 \mathrm{H}_{2} \mathrm{O}\right)$, also known as struvite [14]. The principal factor causing this type of stones is chronical urinary tract infection, but some anatomic predispositions can be also involved. Urease producing bacteria like Proteus, Klebsiella, Pseudomonas, Staphylococcus or Ureaplasma urealyticum, are usually isolated on the urine tests. The rapid growth can also affect the renal pelvis and the calyces. Staghorn calculi are classically associated with infection lithiasis.

Cystine nephrolithiasis is considered to be caused by inherited alterations in the renal transport by some specialists [16], but Sir Archibald Garrod explained this condition as a defect in the metabolic enzymes [17].

This study aims to determine the existence of changing aspects in the chemical composition characterizing this disease and the influence on the treatment and complication rate.

\section{Experimental part \\ Material and method}

We retrospectively analyzed 75 patients with staghorn stone disease admitted in the hospital who underwent PCNL between 01.01.2018 and 31.06.2018. Descriptive data such as age, sex, environment and history of lithiasis 

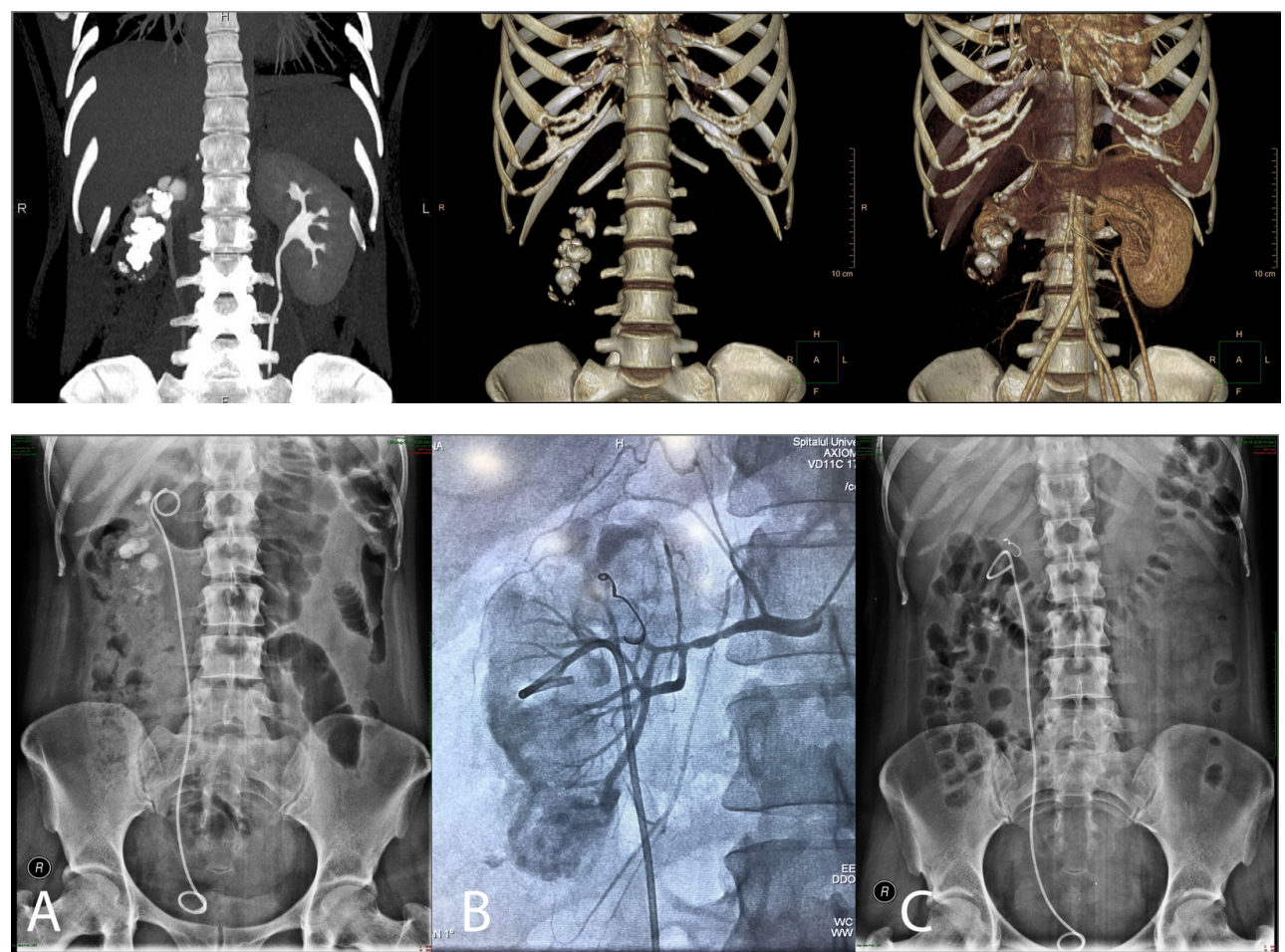

Fig. 1. CT scan and 3D reconstruction for right staghorn calculus type $\mathrm{A}$
Fig. 2. A. KUB after first session of PCNL; B. C. Angiography with embolization and KUB after second session of PCNL was collected from the medical records. All the cases were primarily assessed with complete blood and urine tests before surgery. Prior to surgical intervention, the patients received antibiotic treatment until sterilization of urine was obtained in the cases of urinary tract infection. Preoperative the imagistic evaluation of all patients included Intravenous Urography or CT scan with contrast (fig. 1). Noncontrast CT was selectively done in patients with serum creatinine higher than $1.6 \mathrm{mg} / \mathrm{dL}$.

Based on Moores O'Boyle classification for staghorn calculi, there were selected only Type A, B and C. All the procedures were performed under fluoroscopic control after retrograde placement of an ureteral catheter. We did not use ultrasound imagistic guiding punction. Alken coaxial telescopic dilators to 30 French were used to perform the dilation tract. All cases were performed on Amplatz sheath. Fragmentation and extraction were made with ultrasonic and pneumatic lithotripters and regular clamps. When residual stones were suspected, intraoperative fluoroscopy was made. At the end of the operation a Double JJ stent, 22 French nephrostomy or 48 hours ureteral stent was placed, depending on the complexity of the case [6,7]. All patients underwent KUB (kidneys, ureters and bladder radiography) control after $48 \mathrm{~h}$ (fig. 2).

Complications were evaluated using the Clavien-Dindo system scale, which consists of 7 grades: I, II, IIIa, IIIb, IVa, IVb and V [6]. Chemical composition was determined using chemical qualitative method [11]. Infection stones were considered calculi with magnesium ammonium phosphate (struvite) and calcium carbonate ones. Calcium oxalate, calcium phosphate, calcium mono hydrogen phosphate, cysteine and uric acid were considered types of metabolic stones. Further medication and dietary strategies were indicated based on the chemical tests.

Data was analyzed using Microsoft - Excel software. Simple descriptive statistics were calculated $[18,19]$. Frequency and percentage were calculated for certain variables.

\section{Results and discussions}

Since the first report of PCNL for staghorn stone was made by Clayman etal. [6,20], in 1983, there were multiple studies published that analyzed the techniques, instruments, complication and success rate and stone free status. PCNL still remains the first line of treatment for large renal calculi, in monotherapy or combined with ESWL $[3,21]$. The primary goal is to obtain the stone free status, but this standard is directly related to the case complexity. More and more studies revealed some changing aspects in stones composition that can influence both the stone free status and the complications rate $[6,21]$.

This studyincluded 75 patients, 28 males and 47 females, with a mean age of 53.93 years (min. 19 and max. 80) table 1. No differences were observed about the environment, with $50.66 \%$ of the patients with rural provenance and $49.33 \%$ with urban provenance. 27 cases (36\%) had previous surgical history for renal or ureteral lithiasis and missed the regular surveillance after intervention. In cases with bilateral location, the smallest stone was preferred to start with.

Table 1

PATIENTS CHARACTERISTICS

\begin{tabular}{|c|l|c|c|}
\hline \multicolumn{2}{|c|}{ Variables } & n & $\%$ \\
\hline \multirow{2}{*}{ Sex } & male & 28 & 37.33 \\
\cline { 2 - 4 } & female & 47 & 62.66 \\
\hline \multirow{2}{*}{ Environment } & rural & 38 & 50.66 \\
\cline { 2 - 4 } & urban & 37 & 49.33 \\
\hline \multirow{4}{*}{ Sistory of Lithiasis } & yes & 27 & 36 \\
\cline { 2 - 4 } & no & 48 & 64 \\
\hline \multirow{4}{*}{$\begin{array}{c}\text { Renal Morphology } \\
\text { (hydronephrosis) }\end{array}$} & left & 38 & 50.66 \\
\cline { 2 - 4 } & right & 31 & 41.33 \\
\cline { 2 - 4 } & bilateral & 6 & 8 \\
\cline { 2 - 4 } & gr.I & 48 & 64 \\
\cline { 2 - 4 } & gr.II & 4 & 21 \\
\cline { 2 - 4 } & gr.III & 2 & 2.33 \\
\hline \multirow{2}{*}{$\begin{array}{c}\text { Staghorn type } \\
\text { (Moores O'Boyle } \\
\text { Classification) }\end{array}$} & Type A & 37 & 49.33 \\
\cline { 2 - 4 } & Type B & 36 & 48 \\
\cline { 2 - 4 } & Type C & 2 & 2,66 \\
\hline Urine Culture & Positive & 33 & 44 \\
\cline { 2 - 4 } & Negative & 42 & 56 \\
\hline
\end{tabular}

Urine samples were obtained before surgical intervention and treated with appropriate antibiotics when positive for UTI. In our study, the highest percentage of positive urine culture was observed for Escherichia Coliestimated $27 \%$ as we can see in the Table 2 and figure 3. 
Table 2

UROPATHOGENSIN STUDY GROUP

\begin{tabular}{|l|c|c|}
\hline & $\mathbf{n}$ & $\mathbf{\%}$ \\
\hline Sterile & 42 & 56 \\
\hline E.Coli & 20 & 26.66 \\
\hline Enterococcus & 6 & 8 \\
\hline Proteus & 3 & 4 \\
\hline Staphylococcus & 2 & 2.66 \\
\hline Klebsiella & 1 & 1.33 \\
\hline Pseudomonas & 1 & 1.33 \\
\hline
\end{tabular}

Data existing in specialized literature agree that female gender, having positive urine culture with mostly Proteus species is associated with a struvite composition of the calculi $[2,22]$. According to our data, the positive urine cultures were mostly revealed in the struvite group and E.Coli was the most frequent isolated bacteria (16 cases $42,11 \%$ in this group). Proteus was isolated in 3 cases (4\%), related only to struvite stones and female gender.

Numerous studies showed a different stone compositions across the world, depending on the geographical and etiological factors. One study conducted in France by Daudon et al. revealed that $65.98 \%$ of the analyzed stones were oxalate calculi [23]. Another study on 10.000 urinary calculi, presented by Herring, revealed that $40.9 \%$ were calcium oxalate dihydrate and $31.4 \%$ calcium oxalate monohydrate [24]. One study on the Indian population made some interesting findings in staghorn stone chemical composition of which $89.98 \%$ w ere made of oxalates and only $4.02 \%$ were struvite. This finding appears to be in contrast with the classical theory that staghorn calculi predominantly compounds of struvite and are caused by recurrent urinary tract infections [25].

The difference in stones chemical composition in opposite regions across the word leads to the idea that socio-economical, geographical and etiological factors may change some important aspects of the classical theories.
All 75 patients underwent a total of 104 sessions of PCNL depending on the complexity of the case, the patients' health status and the biochemical stone composition. According to Table 3, in $61.33 \%$ of the cases, a single PCNL session was needed, while in $38.66 \%$ of the cases the patients were treated in two sessions procedure. Urinary drainage was assured in all cases. In $16 \%$ cases only a ureteral catheter for 48 hours was installed. 52\% received a double I stent which was maintained for 3 weeks and in $32 \%$ percent a $22 \mathrm{Fr}$. nephrostomy was placed. Kidney nephrostomy was preferred when infectious signs or massive intraoperatory bleeding was observed and also in cases where second step intervention was considered.

In the cases were residual stones were evaluated, we completed the therapy with one or more sessions of ESWL $[6,14]$.

Residual lithiasis was determined with KUB and ultrasonography. According to Moores O'Boyle classification for staghorn calculi we included 3 groups in our study. As it was expected, the highest rate for residual stones was observed in Type A group (18.66\%) and no residual stone in the Type $C$ group - figure 4 . For residual stones bigger than $5 \mathrm{~mm}$, patients underwent some ESW L sessions until stone free status was reached.

Urinary drainage was used according to the complexity of the intervention, the intraoperative complications, the stone dimension or the expected stone free rate. Ureteral catheters for 48 hours were placed in cases with expected stone free status. $22 \mathrm{Fr}$. nephrostomy was preferred when intraoperative bleeding or local infection was observed and also in cases that undergone a second procedure. 20 cases from the Type A group received nephrostomy in contrast with the Type $C$ group were only double J stent was preferred.

The correlation graphics between stone type and complications according to Modified Clavien-Dindo Classification for PCNL revealed $3 \mathrm{~A}$ and $3 \mathrm{~B}$ complications

\begin{tabular}{|l|l|c|c|}
\hline \multicolumn{2}{|c|}{} & $\mathbf{n}$ & $\%$ \\
\hline Number of sessions & 1 & 46 & 61.33 \\
\cline { 2 - 4 } & 2 & 29 & 38.66 \\
\hline \multirow{4}{*}{ Postoperative Drainage } & JJ stent & 39 & 52 \\
\cline { 2 - 4 } & Nephrostomy & 24 & 32 \\
\cline { 2 - 4 } & Ureteral stent-48h & 12 & 16 \\
\hline Residual stones & Type A & 14 & 18.66 \\
\cline { 2 - 4 } & Type B & 5 & 6.66 \\
\cline { 2 - 4 } & Type C & 0 & 0 \\
\hline
\end{tabular}

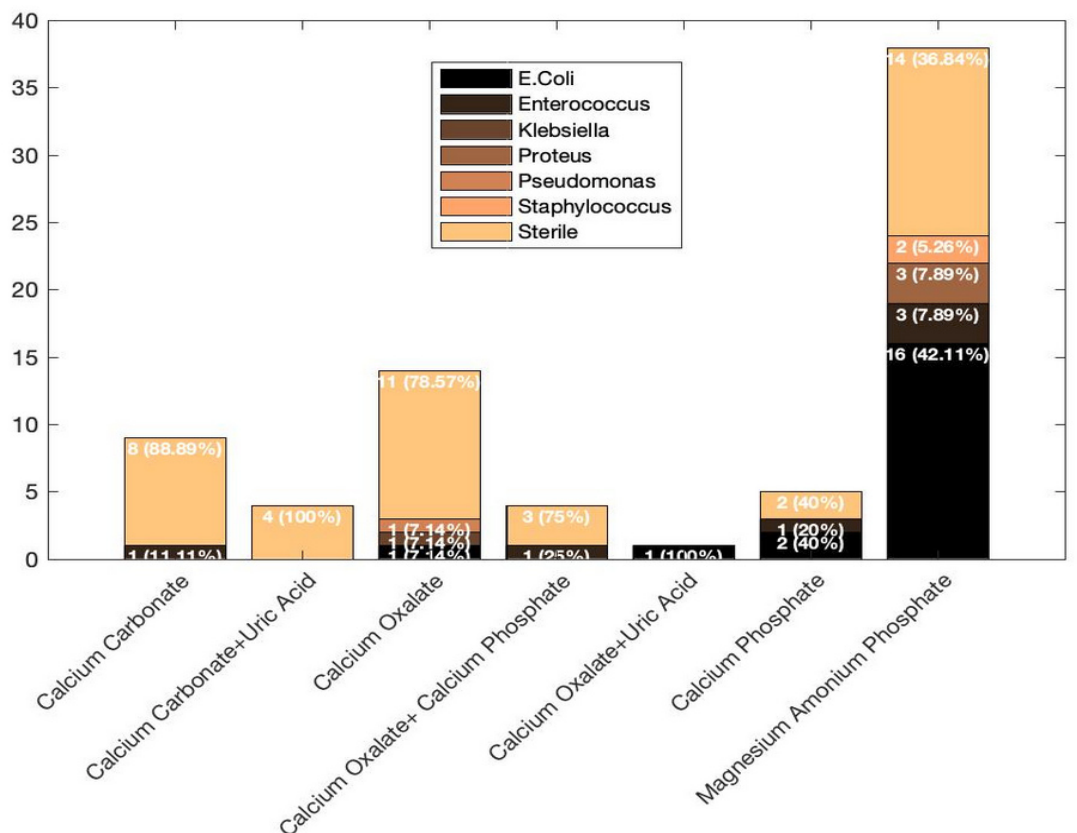

Table 3

INTRA-AND POSTOPERATIVE CHARACTERISTICS

Fig. 3. Correlation between chemical structure of staghorn lithiasis and urine culture 


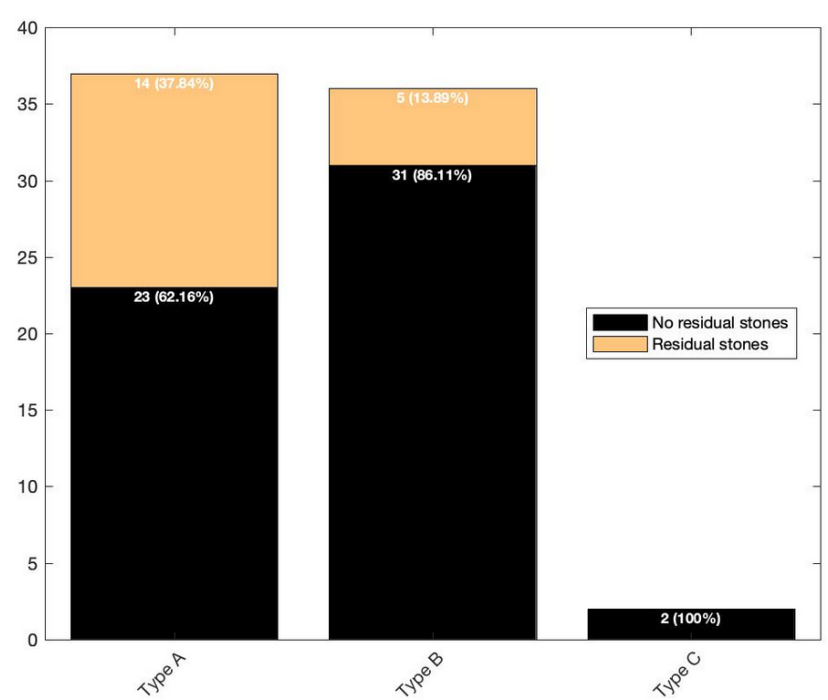

Fig. 4. Correlation between staghorn type and residual stones

grade only in Type A group. No complications were observed in the Type C group. Grade 1 complications had the highest rate in both Type A and B groups - figure 5.

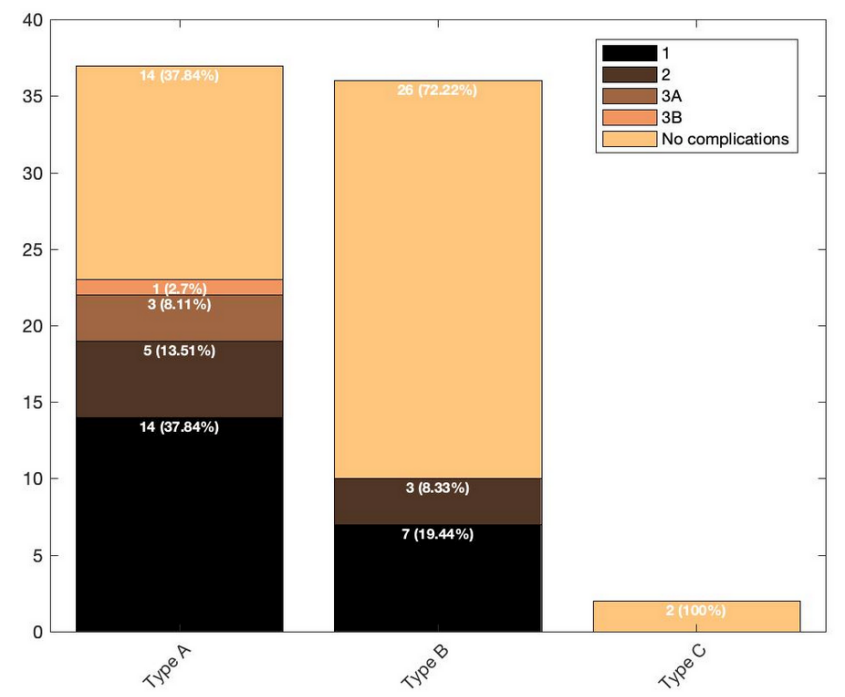

Fig. 5. Correlation between staghorn type and complications according to the Clavien - Dindo Classification

The overall percentage of complications was $44 \%$ with mostly minor complications - grade 1. Hemorrhagic complications were primarily treated with blood transfusions and hemostatic drugs. Nephrostomy clamp and lumbar compression was also applied. 1 case required angiographic embolization for massive bleeding. Urinary leakage was observed after removing the ureteral catheter for 48 hours and after extraction of the nephrostomy. It was treated under local anesthesia with double J stent. Perirenal urinoma was drained with percutaneous drainage tube placed under ultrasonographic guidance. Postoperatively fever was managed with specific antibiotics and antipyretics.

Non-significant results were obtained when we tried to compare the chemical structure with the residual stone after the procedure - figure 6 . The all in all percentage for residual stones was 25.33 for the 75 analyzed cases. A minor increase in percentage for residual stones, about $35.71 \%(n=5)$, was revealed in the calcium oxalate group. The explanation may reside in the hardness of the composition. In the magnesium phosphate group, we can observe that only $13.15 \%,(n=5)$ were diagnosed with residual stones after the postprocedural imagistic evaluation.

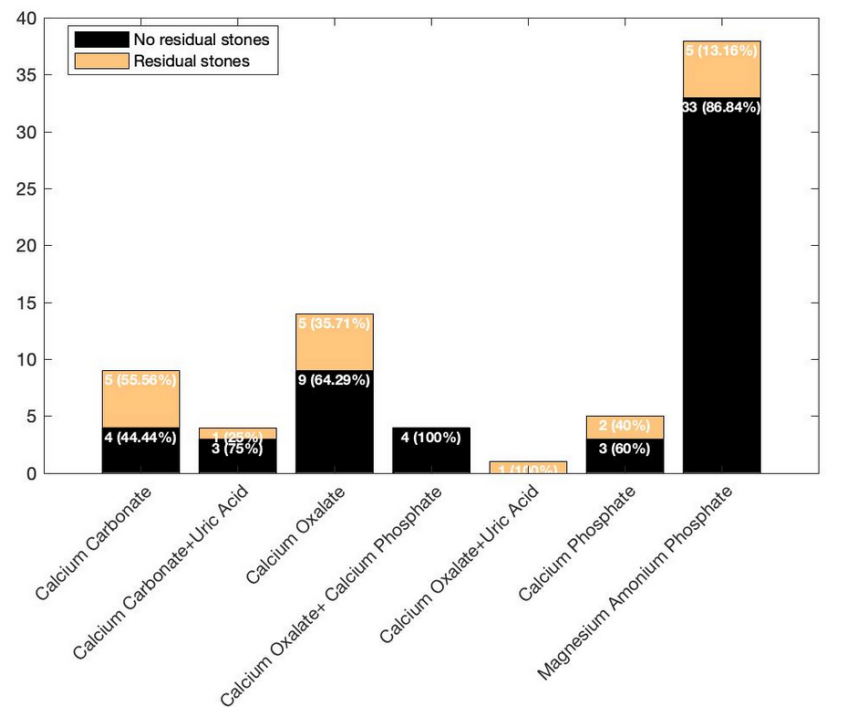

Fig. 6. Correlation between chemical structure and residual stones

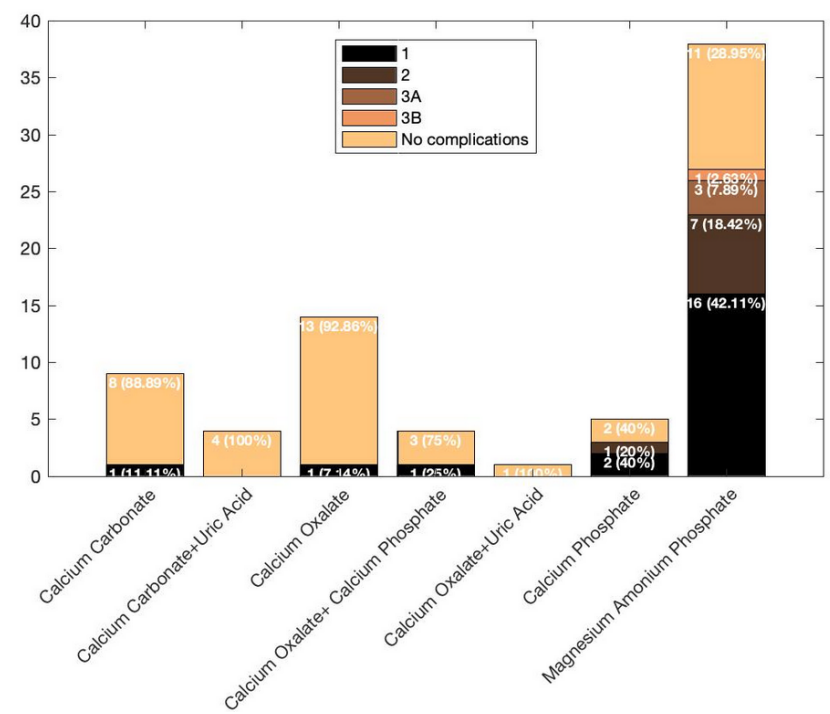

Fig. 7. Correlation between chemical structure and complications according to the Clavien - Dindo Classification

The main risk factor for developing complications after PCNL is considered to be human related and includes: the surgeon's abilities in gaining the percutaneous tract, intrarenal manipulations and techniques used for stone fragmentation and extraction [26]. Considering the above, in our study, less experienced surgeons have enrolled higher complications rate, thus we recommend mixt surgeon teams, which include an experienced endourologist for better results and shorter learning curve.

Urinary tract infection is considered to be the second important risk factor in developing complications after PCNL. Even though the patients with positive urine test were treated preoperatively, the complication rate appears to be lower in the patients with negative urine tests. Fever and sepsis are directly related to the positive urine culture but others risk factors, such as intraoperative bleeding or the postoperative hematuria and urinary leakage appears to be influenced too.

Complications in PCNL varies from prolonged bleeding to organ injuries (pleura, duodenum, colon, spleen, liver) which are related to the access towards the kidney, to septicemia, extravasation and fluid absorption related to the stone removal.

In our study, after the 90 days imagistic evaluation, the all in all stone free rate, for all chemicals compositions, 
was $74.66 \%$, this result being comparable to the results published in AUA guidelines panel for staghorn calculi [3].

The complications rate related to $P C N L$ varies in range between $7 \%-27 \%$ according to AUA nephrolithiasis guidelines panel on staghorn stones. Other contemporary studies report a range of complication rate, based on the modified Clavien system, between $29 \%$ and 37\% [27]. Some other current studies reveal a total complication rate up to $83 \%$ with most frequent complications being mild fever and bleeding without clinical signification [28]. In our study, the overall complication rate after all the procedures was $44 \%$.

According to the Clavien-Dindo classification, we included $28 \%$ of cases $(n=21)$ in Grade $1,11 \%(n=8)$ in Grade $2.4 \%(n=3)$ in Grade $3 A$ with only $1 \%(n=1)$ being Grade 3B. No Grade 4 and 5 were observed. The most frequent complications appeared in the magnesium ammonium phosphate group - figure 7. In the 38 cases analyzed, we had 11 without complication, 16 - Grade 1, 7 - Grade 2, 3-Grade 3A, 1-Grade 3B. Bleeding is considered the most severe complication associated with PCNL and can depend on the complexity of the procedure and the need of multiple tracts [26]. Most of the time, the bleeding can be conservatively managed with lumbar compression, nephrostomy clamp and hemostatic drugs. In severe cases renal angiography with supraselective embolization should be performed. In our study we had only 1 case of persistent bleeding that underwent renal embolization.

Typically, staghorn renal calculi imply a large configuration with extension from the renal pelvis to one or more calyces and are associated with infections. According to AUA guidelines the most frequent staghorn calculi chemical composition is magnesium ammonium phosphate (struvite) and calcium carbonate (apatite) and rarely uric acid, calcium oxalate, calcium phosphate or cystine [3]. In our study we grouped magnesium ammonium phosphate and calcium carbonate as infectious group and the rest as metabolic group. Taking this into consideration we had $62.66 \%$ (47/65) in the pure infectious group and $37.33 \%(28 / 65)$ in the metabolic group. Some studies revealed infectious components in 59-68\% cases of staghorn stones [29]. Another study conducted by Resnick and Boyce on 27 female patients with bilateral staghorn calculi revealed $74 \%$ cases of infectious components [30].

Some recent studies reviews showed an increased incidence for metabolic stones (from 1\% to $5.9 \%$ ) and a decrease for infectious stones (2.6\%) [31]. These changing aspects seem to be associated with weight gaining in population [32,33]. Insulin resistance and metabolic syndrome appears to be responsible for uric acid and calcium oxalate calculi $[12,34,35]$. There are also some studies that describe increased incidence for calcium phosphate stones and a trend for conversion from calcium oxalate to calcium phosphate [31,36]. Calcium phosphate calculi seems to be related with collecting duct injuries, interstitial fibrosis and renal cortical disease with a major impact in patients with staghorn stone disease [37]. Modifications in stone composition can also be related to ethnicity and geographic factors. One study based on population in India revealed that $90 \%$ of the staghorn calculi had in composition calcium oxalate as major chemical component [38]. Our conducted study still revealed a major component $62.66 \%$ for struvite and apatite.

\section{Conclusions}

PCNL is the gold standard procedure for large renal stones with a high success rate, performed in one or more session. Even though, performing this surgical technique in more session can lead to an increased number of complications, in most of the cases they are minor.

A large number of cases of staghorn calculi present with urinary tract infections so it is important to correctly investigate the patients and treat the eventual positive urine cultures with proper antibiotics before the procedure. This can significantly decrease the number of complications.

As more and more studies reveal some changes in the staghorn calculi chemical structure, this study sought to analyze some correlations between the structures, stone free status and complications. It appears that we did not found a correlation between the chemical structure and the stone free rate, even though a slightly increased number of residual stones was observed in the calcium oxalate group.

The number of complications after PCNL can vary a lot from case to case, but it is generally accepted to be a safe procedure with a low percentage of major complications with impact on the patient's health status. Complications rate seems to be influenced by the stone length and the chemical structure. Clavien Dindo grade $3 \mathrm{~A}$ and $3 \mathrm{~B}$ were observed only in cases of complete staghorn calculi and also an increased percentage of minor complications were observed in the struvite type, maybe because of the frequent association with urinary tract infections.

\section{References}

1.SEGURA, J. W. Urol. Clin. North. Am., 24, no. 1, 1997, p. 71.

2.GETTMAN, M. T., SEGURA, J. W. J. Endourol., 13, no. 9, 1999, p. 653. 3.PREMINGER, G. M., ASSIMOS, D. G., LINGEMAN, J. E., NAKADA, S. Y., PEARLE, M. S., WOLF, J. S. J. Urol., 173, no. 6, 2005, p. 1991.

4.HEALY, K. A., OGAN, K. Urol. Clin. North. Am., 34, no. 3, 2007, p. 363. 5.RUDNICK, D., STOLLER, M. Can. J. Urol., 6, no. 5, 1999, p. 872.

6.AMBERT, V., BRATICEVICI, B., SALLAHEDIN, Y., PETCA, R. C., HAINAGIU, L., CALIN, C., DIACONESCU, D. Eur. Urol. Suppl. 9, no. 2, 2010, p. 36

7.AMBERT, A., BRATICEVICI, B., JINGA, V., DIACONESCU, D. S., POPESCU, M. C., CALIN, C., ... \&, DOROBAT, B. Eur. Urol. Suppl. 9, no. 6, p. 660.

8.DE LA ROSETTE, J. J., OPONDO, D., DAELS, F. P. Eur. Urol., 62, no. 2, 2012, p. 246.

9.RANDALL, A. Ann. Surg.,105, no. 6, 1937, p. 1009.

10.MOE, O. W. Lancet, 367, no. 9507, 2006, p. 333.

11.PUPCA, G., BUCURAS, V., VLASE, G., VLASE, T., FULIAS, A. LEDETI, I. Rev. Chim.(Bucharest), 65, no. 9, 2014, p. 1058.

12.TIMOFTE, D., OCHIUZ, L., URSARU, M., CIUNTU, B., IONESCU, L., CALU, V., MOCANU, V., PUIA, I. C. Rev. Chim.(Bucharest), 68, no. 10, 2017, p. 2341.

13.PAK, C. Y., SAKHAEE, K., PETERSON, R. D., POINDEXTER, J. R., FRAWLEY, W. H. Kidney Int., 60, no. 2, 2001, p. 757.

14.PETCA, R. C., POPESCU, R. I., MEHEDINTU, C., BOT, M., VEDUTA, A., PETCA A. Proceedings Of The 6th Congress Of The Ultrasound Society In Obstetrics And Gynecology / 34th Fetus As A Patient International Congress, Bucharest, 2018, p. 478.

15.MATEI, L., PANAITESCU, E., DOGAROIU, C. Rom. J. Leg. Med., 20, no. 3, 2012, p. 223.

16.DENT, C. E., ROSE, G. A. QJ Med, 20, 1951, p. 205.

17.SCRIVER, G. R. J. Inherit. Metab. Dis., 24, 2001, p. 93.

18.BRATICEVICI, B., PETCA, R., PETRESCU, A., JINGA, V., IONITA, L. Rom. Biotechnol. Lett., 19, no. 1, 2014, p. 9051.

19.VEDUTA, A., PETCA, R., PETCA, A. Proceedings Of The 14th National Congress Of Urogynecology And The National Conference Of The Romanian Association For The Study Of Pain, Eforie, 2017, p. 199. 20.CLAYMAN, R. V., SURYA, V., MILLER, R. P. JAMA, 250, 1983, p. 73. 21.BARBILIAN, R. C., CAUNI, V., MIHAI, B., BURAGA, I., DRAGUTESCU, M., JINGA, M., MISCHIANU, D. Rev. Chim.(Bucharest), 69, no. 12, 2018, p. 3745. 
22.MEHEDINTU, C., ANTONOVICI, M., BRINDUSE, L., BRATILA, E., STANCULESCU, R., BERCEANU, C., ...\&, MATASARIU, D. R. Rev. Chim.(Bucharest), 69, no. 3, 2018, p. 581.

23.DAUDON, M., DOSIMONI, R., HENNEQUIN, C. Ureol. Res., 23, 1995, p. 319.

24.HERRING, L. C. J. Urol., 88, 1962, p. 545.

25.ANSARI, M. S., GUPTA, N. P., HEMAL, A. K., DOGRA, P. N., SETH, A., ARON, M., SINGH, T. P. Int. J. Urol., 12, no. 1, 2005, p. 12.

26.EL-NAHAS, A. R., SHOKEIR, A. A., EL-ASSMY, A. M., MOHSEN, T., SHOMA, A. M., ERAKY, I. J. Urol, 177, 2007, p. 576.

27.TEFEKLI, A., KARADAG, M. A., TEPELER, K., SARI, E., BERBEROGLU, Y., BAYKAL, M., MUSLUMANOGLU, A. Y. Eur. J. Urol., 53, 2008, p. 184. 28.SEGURA, J. W., PATTERSON, D. E., LEROY, A. J., WILLIAMS, H. J., BARRETT, D. M., BENSON, R. C., ... \& BENDER, C. E. J. Urol., 134, 1985, p. 1077.

29.WALL, I., HELLGREN, E., LARSSON, L., \& TISELIUS, H. G. Urology, 28, no.5, 1986, p. 377.

30.RESNICK, M. I., BOYCE, W. H. J. Urol., 123, no. 3, 1980, p. 338.

31.MANDEL, N., MANDEL, I., FRYJ OFF, K., REJ NIAK, T., MANDEL, G. J. Urol., 169, no. 6, 2003, p. 2026.
32.FLEGAL, K. M., CARROLL, M. D., OGDEN, C. L., JOHNSON, C. L. Jama, 288, no. 14, 2002, p. 1723.

33.DIACONU, C. C., STANESCU, A. M. A., PANTEA STOIAN, A., TINCU, R. C., COBILINSCHI, C., DRAGOMIRESCU, R. I. F., .. \& BRATU, O. G. Rev. Chim. (Bucharest), 69, no. 6, 2018, p. 1367.

34.ABATE, N., CHANDALIA, M., CABO-CHAN JR, A. V., MOE, O. W., \& SAKHAEE, K. Kidney Int., 65, no. 2, 2004, p. 386.

35.CUPISTI, A., MEOLA, M., D'ALESSANDRO, C., BERNABINI, G., PASQUALI, E., CARPI, A., BARSOTTI, G. Biomed Pharmacother., 61, no. 1, 2007, p. 86.

36.PARKS, J. H., WORCESTER, E. M., COE, F. L., EVAN, A. P., LINGEMAN, J. E. Kidney Int., 66, no. 2, 2004, p. 777.

37.EVAN, A. P., LINGEMAN, J. E., COE, F. L., SHAO, Y., PARKS, J. H., BLEDSOE, S. B., ... \& KIM, S. A. M. C. Kidney Int., 67, no. 2, 2005, p. 576.

38.ANSARI, M. S., GUPTA, N. P., HEMAL, A. K., DOGRA, P. N., SETH, A., ARON, M., \& SINGH, T. P. Int. J. Urol., 12, no. 1, 2005, p. 12.

Manuscript received: 18.06 .2019 